\section{O astrolábio, o mar e o Império}

\section{The astrolabe, the sea and the Empire}

\section{Heloisa Meireles Gesteira}

Pesquisadora, Museu de Astronomia e Ciências Afins (Mast); professora, Programa de Pós-graduação em História Social/ Universidade Federal do Estado do Rio de Janeiro/Mast, Pontifícia Universidade Católica do Rio de Janeiro.

$$
\text { Mast }
$$

Rua General Bruce, 586

20921-030 - Rio de Janeiro - RJ - Brasil

heloisagesteira@mast.br

Recebido para publicação em abril de 2013.

Aprovado para publicação em março de 2014.
GESTEIRA, Heloisa Meireles. O astrolábio, o mar e o Império. História, Ciências, Saúde-Manguinhos, Rio de Janeiro, v.21, n.3, jul.-set. 2014, p.10111027.

\section{Resumo}

A partir de alguns textos escritos pelos cosmógrafos do Reino, entre os séculos XVI e XVIII, em Portugal, pretendemos evidenciar as bases técnicas e científicas que possibilitaram a expansão marítima europeia destacando as relações entre elas e a construção e o uso dos instrumentos matemáticos utilizados na navegação oceânica. Nosso objetivo, além de sublinhar os conteúdos científicos relacionados aos artefatos utilizados para as medições, é também verificar como a ciência e o conhecimento adquirem significado prático, estratégico e simbólico no contexto da expansão ultramarina de Portugal.

Palavras-chave: descobrimentos; instrumentos matemáticos; Império português; Portugal.

\section{Abstract}

Based on certain texts written by Portugal's cosmographers of the kingdom between the sixteenth and eighteenth centuries, we bring to light the technical and scientific foundations for the European maritime expansion, highlighting the relationships between them and the making and use of the mathematical instruments used in ocean navigation. Our objective is not just to underline the scientific aspects of the artefacts used for these measurements, but also to ascertain how science and knowledge acquired a practical, strategic and symbolic meaning within the context of Portugal's expansion overseas.

Keywords: discoveries; mathematical instruments; Portuguese Empire; Portugal. 
E ficam também desaparecendo as carrancas, e os horrores da imensidade dos mares do Oceano entre a América, e as outras partes do mundo que pareciam perpetuamente inavegáveis. Estes temores têm desaparecido como fumo, à vista dos generosos corações da gente Portuguesa e Castelhana, que tem corrido o mundo todo, experimentando os polos mais distantes, Ártico, e Antártico; passado climas, regiões, e zonas nunca dantes vistas. Para isto souberam achar 'instrumentos', e armar vasos em o mar, que pareciam cidades portáteis, assombro das nações estrangeiras, e em cuja comparação desaparecem as afamadas navegações dos Eneas, Jasões, Ulisses

(Vasconcelos, 1864, p.35; destaque meu)

Desde o início do século XV, com a chegada em Ceuta em 1415, cada vez mais a Coroa portuguesa alastrou os seus domínios tendo como veio de comunicação as rotas do Atlântico. A cada avanço, que teve como marcos decisivos para os interesses portugueses no Atlântico a passagem para a Índia, alcançada por Vasco da Gama em 1498, e o desembarque de Pedro Álvares Cabral no Novo Mundo, ampliava-se o conhecimento acumulado sobre as rotas, sobre as condições de navegação no hemisfério Sul, sobre povos que habitavam áreas até então desconhecidas e sobre novos produtos que passaram a fazer parte do comércio. Mesclavamse os interesses mercantis e políticos, ambos justificados ideologicamente pelos interesses do catolicismo, como apontado por Charles Boxer (1992) quando considerou as bulas Romano Pontifex, de janeiro de 1455, e Inter Caetera, de março de 1456, documentos importantes para entender o colonialismo ibérico da época moderna.

Se os impulsos da expansão portuguesa podem ser identificados na política, na economia e na evangelização de povos não cristãos, o que deu condições ao empreendimento português foram o conhecimento e a técnica disponíveis aplicados aos problemas náuticos. A navegação oceânica, realizada distante da costa, trouxe desafios que foram solucionados no encontro entre a astronomia e a náutica: em pleno mar, o único ponto fixo para orientação das embarcações eram as estrelas, no hemisfério Norte a Polar. A proximidade do Equador e o avanço para o Sul tornaram o Sol uma estrela-guia, somado às estrelas do Cruzeiro do Sul.

Os pilotos dos "descobrimentos"1 eram munidos de instrumentos, tabelas de declinação do Sol e de outras estrelas conhecidas, roteiros e informações sobre as condições de navegação. Tudo visando à condução correta das embarcações rumo ao ponto desejado, mas igualmente permitindo o mapeamento das linhas costeiras e das novas terras. Durante as viagens, novas anotações eram feitas com a finalidade de aprimorar os dados coletados pelos pilotos e homens do mar.

Os "instrumentos" que os ibéricos "souberam achar" e adaptar para a navegação no oceano Atlântico foram astrolábios, bússolas, quadrantes, balhestilhas, além de outros artefatos como compassos, transferidores e réguas, que serviam para transportar os dados coletados para a superfície do papel, permitindo o aperfeiçoamento das cartas de marear. Some-se a isso a acumulação de conhecimento sobre as correntes marítimas e sobre os sistemas de vento do Atlântico Sul, elemento de ligação entre os quatro continentes. 
Neste trabalho pretende-se uma leitura de alguns tratados de navegação, em particular os textos de Manuel Pimentel. Interessam-nos os trechos que discorrem sobre os usos e descrições dos instrumentos necessários para as navegações oceânicas e as partes relativas aos roteiros, o que também poderia ser denominado hidrografia. Conforme o Vocabulário português e latino, de Raphael Bluteau (1728, p.79), a palavra era definida da seguinte forma: "Propriamente é a descrição do elemento da água, dos mares e ilhas ... Mas de ordinário toma-se pela ciência, que ensina a arte de navegação, o modo de fazer cartas de marear". O vocábulo seguinte, hidrográfico, relaciona-se ao anterior e remete para carta hidrográfica, "para uso dos pilotos, se apontam os diferentes rumos, os baixios, e bancos de areia".

A partir de alguns textos escritos pelos cosmógrafos do Reino, entre os séculos XVI e XVII, pretendemos evidenciar as bases técnicas e científicas que possibilitaram a expansão marítima europeia destacando as relações entre elas e os "instrumentos", bem como seu uso. Nosso objetivo, além de sublinhar os conteúdos científicos relacionados aos artefatos utilizados para as medições, é também verificar como a ciência e o conhecimento adquirem significado prático, estratégico e simbólico no contexto da expansão ultramarina de Portugal. Somamos ao texto em epígrafe a passagem da Arte de Navegar, de Manuel Serrão Pimentel (1681, p.II), contida na dedicatória ao rei dom Pedro II de Portugal: "Pela necessidade e utilidade da obra, cujo fim é o ditoso acerto das navegações e conquistas deste Reino".

Entre os séculos XV e XVI as navegações sofreram transformações significativas, embora difíceis de datar precisamente. Alguns procedimentos que caracterizavam a arte de navegar dos descobrimentos foram inaugurados pelos portugueses durante a exploração do Atlântico ainda no decorrer dos anos 1400. Eram eles: a navegação por alturas e distâncias de um astro (inicialmente a estrela Polar); a simplificação do astrolábio para uso náutico; a confecção do regimento do Sol, para os cálculos de latitude, por meio da relação entre a altura meridiana do astro e a declinação num determinado dia; a preparação de tabelas de declinação do Sol e estrelas mais visíveis de constelações conhecidas; um levantamento cada vez mais detalhado da costa africana por meio da determinação de latitudes; e um conhecimento cada vez melhor do Atlântico. Tais métodos permaneceram dominantes até meados do século XVIII, quando foram criados novos instrumentos que possibilitavam a determinação da longitude no mar, como o octante, instrumento de reflexão cuja invenção é atribuída ao astrônomo inglês John Hadley. Os avanços do conhecimento geográfico e astronômico, somados ao desenvolvimento de instrumentos cada vez mais precisos, principalmente fabricados na França e na Inglaterra, foram responsáveis pelas inovações (Guedes, 1999, p.14; Furtado, 2011).

O uso de instrumentos foi imprescindível para as observações astronômicas relacionadas ao posicionamento geográfico das embarcações durante as viagens oceânicas, para a definição das rotas, para a confecção de roteiros e, não menos importante, para a localização das novas terras. Nesse contexto, muda também a cultura necessária para se conduzir uma nau. A carta assinada por dom João III em dezembro de 1547, nomeando Pedro Nunes como cosmógrafo-mor do Reino, marcou o início da organização mais sistematizada do ensino náutico, com a preparação dos pilotos e com um controle por parte da Coroa, conforme estipulado no Regimento dos pilotos, só publicado em 1592. O regimento definia as atribuições dos cosmógrafos-mores, que eram ainda responsáveis pelas demarcações internas do Reino e pelos limites externos. $\mathrm{O}$ documento permaneceu basicamente sem alterações durante 
muitos anos, somente em 1679 algumas modificações foram inseridas. A partir de 1779, com a criação da Academia Real da Marinha, a preparação de pilotos e cartógrafos ficou sob responsabilidade dessa instituição (Matos, 1999; Kantor, 2012).

O documento de 1592 é claramente um reflexo das necessidades da navegação astronômica, mas também aponta para a articulação entre os interesses políticos e a importância que o controle sobre as rotas e localização de terras distantes passou a ter na geopolítica europeia: o domínio sobre as técnicas era um dos elementos-chave. O regimento previa para os pilotos o ensino de noções básicas de matemática ligadas à navegação. Seguindo as instruções, os pilotos receberiam lições sobre "A declaração de alguns círculos da esfera e para o que lhes hão de servir, o ensino sobre a figura do universo"; apresentar a "figura do universo e como se faz o diurno movimento do primeiro móbil e do Sol e da Lua", transmitir regras sobre a Lua e o conhecimento das marés; explicar a utilização da carta de marear e a manipular o astrolábio, "ensinando-lhes a tomar o Sol e como hão de usar o regimento" para fazer os cálculos corretamente determinando a altura do astro ao meio-dia; aprender a usar a balhestilha e o quadrante para "a noite tomarem a altura da estrela" e "calcular a altura do polo"; dar instruções sobre como nordestear e noroestear com o uso da agulha; e, finalmente, os mais habilidosos eram treinados para usar o astrolábio de lâminas e outros instrumentos, e seriam submetidos à leitura do Tratado da esfera (Mota, 1969, p.32-33).

A difusão do Tratado da esfera, de Johannes de Sacrobosco, em Portugal, foi marcada pela publicação, em 1537, de uma tradução da obra feita pelo matemático e cosmógrafo Pedro Nunes, embora o texto já circulasse em forma manuscrita antes dessa data (Albuquerque, 1959; Camenietzki, 2011). Além de o Tratado ser uma espécie de livro didático para aqueles que se iniciavam na astronomia durante a época moderna, era também ponto de partida obrigatório para aqueles que aprendiam a arte de navegar, sobretudo para uso dos instrumentos, mas nesse caso os livros não se estendiam em comentários críticos sobre o tema, como era mais frequente nos livros de astronomia, inclusive entre os matemáticos da Companhia de Jesus. Diferente de obras que se dedicavam à filosofia natural, os livros de navegação apresentavam apenas os princípios básicos da esfera, as noções necessárias para a navegação: redondeza da terra (composta por terra e água), os círculos máximos, os meridianos e o horizonte, os círculos menores, os trópicos de Câncer e de Capricórnio, o eixo e os polos, o que é zênite (relativo ao observador) e o que é latitude e longitude.

Em relação aos instrumentos, o documento indicava a importância do controle sobre sua fabricação, em particular quanto aos problemas relativos a sua graduação. Embora não houvesse detalhamento, cabia ao cosmógrafo examinar o instrumento, e o regimento previa: "Não poderá pessoa alguma, qualquer que seja daqui por diante fazer cartas de marear, quarteirões, globos, astrolábios, quadrantes, agulhas, balhestilha, regimentos da altura do polo e declinação do Sol e relógios" (Mota, 1969, p.13-14). Em relação às cartas, "serão conforme o padrão que disso há no armazém sem mudar, encurtar, nem acrescentar coisa alguma dos mares, costas e terras que estiverem lançadas nos ditos padrões" (p.19).

Cabia aos cosmógrafos examinar os instrumentos e as cartas feitas pelos candidatos a piloto. E aqueles que fossem denunciados utilizando outros padrões, conforme o Regimento, cumpririam pena de degredo na África. A padronização tanto das cartas como dos instrumentos tornara-se extremamente importante, pois as disputas sobre a localização das terras muitas 
vezes eram resolvidas com a ajuda dos cartógrafos e cosmógrafos do Reino, que eram responsáveis, como já dissemos, pelas demarcações. Essa aproximação entre o ofício de cartógrafos e cosmógrafos do Reino com os interesses geopolíticos da monarquia nos permite inferir que muitos erros de localização presentes em cartas-padrão, ou náuticas, que eram distribuídas aos pilotos materializassem interesses territoriais e não significassem apenas problemas de precisão ou mau uso dos instrumentos (Sandman, 2002).

Se por um lado a sistematização e o controle atestam o papel que o cosmógrafo passou a ter na política territorial do Reino, indicam igualmente a importância para os Estados europeus de ter homens tecnicamente preparados para a defesa de seus interesses geopolíticos na Europa, mas, sobretudo, no ultramar. Por tudo isso, no contexto de Portugal, o conhecimento sobre o Atlântico Sul era cada vez mais estratégico para sua política ultramarina. Munidos das informações trazidas pelos pilotos e homens do mar, os cosmógrafos, compiladores dos dados recolhidos durante as viagens, transformam-se em servidores imprescindíveis do monarca.

Não pretendemos entrar nas controvérsias sobre até que ponto os pilotos eram bem preparados ou não em Portugal, embora apareçam reclamações acerca desse tema nos livros dedicados à náutica, desde Pedro Nunes até Manuel Serrão Pimentel. Tampouco iremos pesquisar se os exames previstos no regimento foram efetivamente aplicados aos pilotos portugueses, pois a pesquisa seria outra. O que nos interessa explorar é de que maneira esse saber se constituiu nos livros de marinharia (roteiros, informações sobre a declinação magnética dos lugares, tabelas dos graus, minutos e segundos de latitudes e longitudes dos lugares) e até que ponto os instrumentos previam a perícia de quem os usava, tanto para coletar os dados observados como para calcular a partir da consulta às tabelas de declinação dos astros e de localização de lugares. O que nos parece e tentaremos demonstrar é que o uso dos instrumentos nos permite afirmar que, mesmo com homens dotados de um saber prático, os pilotos, ou alguém numa embarcação, deveriam ter controle sobre as regras básicas da arte de navegar.

Para essa reflexão nos dedicaremos mais especificamente a $A$ arte de navegar, texto de Manuel Serrão Pimentel, cosmógrafo-mor durante o reinado de dom João V e filho de Luís Serrão Pimentel, que o antecedeu no cargo. Ainda que a obra e suas diversas edições mereçam estudo mais detalhado por reunir aspectos ligados à cultura náutica portuguesa desde o século XVI até o início do XVIII, pretende-se aqui explorar especificamente as partes relativas ao uso de instrumentos, em particular o astrolábio e a agulha de marear, além da descrição de parte dos roteiros apresentados nas edições de 1681 e de 1818, consultadas para este trabalho.

Manuel Pimentel nasceu em Lisboa a 10 de maio de 1650. Seu pai, Luís Pimentel, além de cosmógrafo-mor, ocupou também o cargo de engenheiro. Ainda adolescente, Manuel frequentou o Colégio de Santo Antão em Lisboa, no qual teve bom desempenho em latim. Dali seguiu para a Universidade de Coimbra, assistindo a aulas de direito e cânones, e concluindo seus estudos em 1674. Provavelmente durante os anos em que esteve no Colégio de Santo Antão, Pimentel teve contato com os estudos de cosmografia lecionados na "Aula da esfera" (Correia, 2010).

Em Portugal, durante os séculos XVI e XVII o Colégio de Santo Antão, da Companhia de Jesus, era um dos centros importantes para os estudos e a difusão da matemática. No decorrer dos séculos XVI e XVII, os professores da renomada "Aula da esfera" nela se dedicavam aos 
temas diversos de filosofia natural, como as discussões sobre a natureza dos corpos celestes. Ali eram debatidas questões polêmicas relativas aos modelos cosmológicos, embora a tendência fosse a adoção das proposições de Tycho Brahe. Se por um lado não se podem reduzir os tópicos ali apresentados e ensinados aos problemas da navegação, nem era esse o sentido da dita aula, os matemáticos da Companhia de Jesus, em Portugal, tiveram papel de destaque na formação intelectual dos cosmógrafos, e alguns se dedicaram a escrever sobre o tema (Albuquerque, 1972; Leitão, 2003). Segundo o próprio Albuquerque (1972, p.9), a "Aula da esfera" mantinha em seu conteúdo alguns tópicos presentes no Regimento dos pilotos, o que, segundo o autor, atraía "fidalgos que desejassem habilitar-se para melhor servir o Rei". Entre eles, seguramente, Manuel Pimentel.

A primeira publicação de Manuel Pimentel, Arte prática de navegar e regimento de pilotos, de 1681, é uma edição póstuma dos trabalhos deixados por seu pai à qual ele acrescenta dados e atualiza tabelas. Ainda no final do século XVII foi publicada Arte prática de navegar e roteiro das viagens e costas marítimas do Brasil, Guiné, Angola, Índias e Ilhas Orientais e Ocidentais, editada em Lisboa, por Bernardo da Costa Carvalho, em 1699. Passados 13 anos, outra edição foi preparada com o título Arte de navegar, em que se ensinam regras práticas e o modo de cartear pela carta plana, e reduzida, o modo de graduar a balhestilha por via dos números, e muitos problemas úteis à navegação, e roteiro das viagens, e costas marítimas da Guiné, Brasil..., também na cidade de Lisboa pela Oficina Real Deslandesiana, em 1712. Essa edição foi publicada diversas vezes, o que denota sua importância na cultura náutica em Portugal: 1746, 1762 e $1819 .{ }^{2}$

A estrutura de Arte de navegar reproduz a organização de obras escritas pelos cosmógrafos que antecederam Manuel Pimentel em Portugal e que se adequavam aos conteúdos previstos no Regimento dos pilotos. Uma primeira parte dedica-se ao conteúdo científico que permite o entendimento da estrutura do universo e sua aplicação à navegação, ou seja, os princípios da esfera, os diversos círculos que a compõem. Em geral, o tópico era completado com tabelas das declinações dos astros que serviam de guia: o Sol e estrelas mais visíveis de constelações - a Polar, no hemisfério Norte, e o Cruzeiro, no hemisfério Sul. Normalmente, após as definições, havia a descrição e forma de uso de instrumentos: agulha de marear, astrolábio, balhestilha e quadrante náutico. Pimentel trata ainda da carta de náutica, seu uso e modo como se deviam registrar informações. Uma segunda parte do livro descreve os roteiros e caminhos pelos quais passam as embarcações.

Navegar é uma "arte"; em outras palavras, tudo que era realizado ou confeccionado a partir de regras estabelecidas com auxílio da ciência. Como arte, a navegação era uma das vias de aplicação prática da matemática e da astronomia. Isso acarretava uma hierarquia intelectual entre o cosmógrafo e o piloto. Não é do nosso interesse investigar até que ponto os pilotos liam ou não essas obras, ou mesmo se eram escritas para esse público ou visavam ao reconhecimento e afirmação do cosmógrafo no âmbito da corte e entre seus pares. O fato é que eram textos voltados para a difusão da arte de navegar e com uma clara intenção de auxiliar aqueles que iam para o mar. Conforme indicado no subtítulo, "em que se ensinam regras práticas", podemos inferir que a intenção desse gênero era ao mesmo tempo ensinar e auxiliar os pilotos, mas também assimilar práticas consagradas pelo uso dos navegantes e inseri-las em obras que buscavam o reconhecimento de autoridade entre os cosmógrafos e outros homens de ciências. É interessante lembrar que entre as transformações que 
contribuíram para a formação da ciência moderna estão a observação de práticas artesanais e sua incorporação em tratados que buscavam estabelecer regras fundamentadas em teorias, ou seja, as técnicas muitas vezes utilizadas por práticos e artesãos passam a fazer parte das reflexões dos filósofos naturais e ganham assim estatuto de ciência (Rossi, 1989). A maior parte dos textos de marinharia por nós consultados não apresenta reflexões de caráter mais especulativo e tem linguagem relativamente acessível, publicada em português e em castelhano, o que não exclui a incorporação de especulações mais sofisticadas, como, por exemplo, os textos mais teóricos de Pedro Nunes em Tratados sobre a carta de marear, trazidos à luz em 1537, junto como a tradução feita para o português do Tratado da esfera; e o de Antonio de Najera, Navegacion especulativa y pratica, publicado em 1628, na cidade de Lisboa. Porém, cabe afirmar que o gênero era escrito visando a interferir na prática dos pilotos, ainda que houvesse resistências e mesmo divergências.

De acordo com o previsto no Regimento dos pilotos, todos os textos de marinharia partem de um comentário sobre a esfera, forma que tem a Terra. Uma primeira noção importante apresentada no início do texto de Pimentel é sobre a composição da "esfera terráquea":

A Terra e o Mar juntamente faz um globo redondo, como uma bola, que lhe chama esfera, e por ser composta destes dois elementos, terra e água, lhe chamam os matemáticos de esfera terráquea ou Globo terráqueo. ... Também posto que o mar pareça plano como hum campo raso, não há dúvida ser redondo, e o parecer plano é engano da vista. Assim como se descrever com o compasso um círculo muito grande, e depois ir apagar, deixando uma porção tamanha como a largura de meio dedo, esta porção ha de parecer linha direita, sendo que é circular, pois foi descrita com o compasso (Pimentel, 1819, p.9).

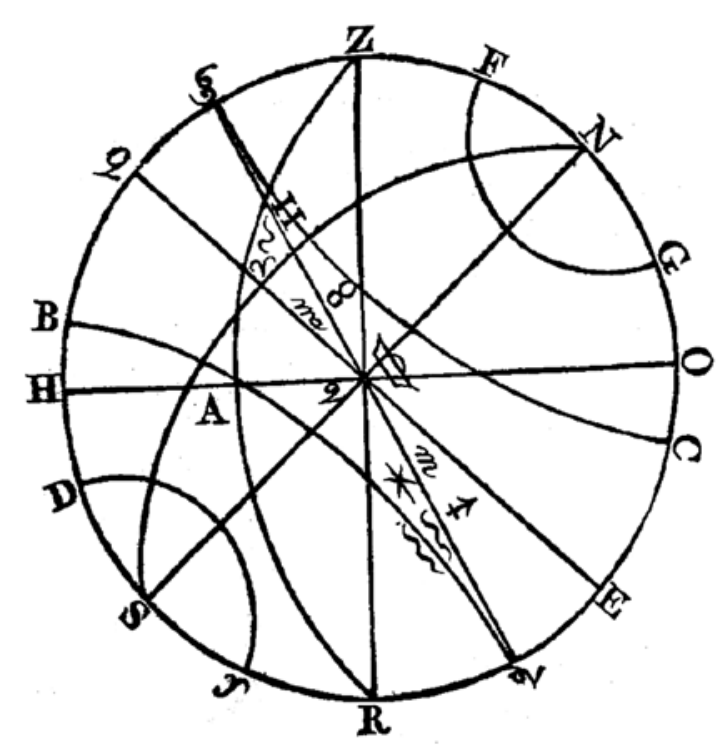

Figura 1: Diagrama demonstrando os círculos e pontos importantes da esfera para realização das observações e identificação do posicionamento geográfico (Pimentel, 1819, p.14)
Em seguida, o cosmógrafo apresenta a definição dos círculos que compõem a esfera uma vez que esse conhecimento é necessário para a realização das observações e para fabricação e uso dos instrumentos.

Num capítulo breve e sem mencionar nenhuma discussão sobre cosmologia, Pimentel defende a posição central da Terra no universo. Em aproximadamente dez linhas conclui que a centralidade pode ser comprovada pelo fato de que, em qualquer ponto em que se esteja, os astros são vistos do mesmo tamanho e movem-se sempre do Oriente para o Ocidente. Ou seja, sem entrar em nenhuma polêmica, o argumento que utilizou para afirmar a posição central da Terra é o ponto de visão, não indicou as diferentes teorias em voga do início do século XVIII e que eram debatidas na "Aula da esfera". ${ }^{3}$ 
Em seguida Pimentel explica por que a esfera foi convencionalmente dividida em 360 graus e cada grau em sessenta minutos, que por sua vez se subdividem em sessenta segundos e das vezes que esses números podem ser divididos em porções exatas, facilitando os cálculos. O cosmógrafo apresenta as equivalências dos graus em distâncias e sugere a conversão de cada grau do círculo em 18 léguas.

A divisão era utilizada para marcar os astrolábios e quadrantes para medir a altura dos astros no mar. Aliás, eis aqui uma novidade importante na cultura dos descobrimentos: a necessidade de se localizar, de se deslocar de um ponto a outro com o mínimo de segurança e de identificar as novas terras impôs a padronização das medidas utilizadas, aspecto presente na fabricação e no desenho dos instrumentos. Além da localização mais precisa, essa padronização das medidas era crucial para reunir as informações anotadas pelos diversos pilotos durante as viagens para os pontos mais longínquos do Império. Os dados serviam para atualizar as cartas-padrão utilizadas pelas embarcações portuguesas que singravam o Atlântico. As cartaspadrão eram feitas pelos cosmógrafos do rei e serviam de base para os pilotos seguirem o rumo e também fazerem anotações durante as viagens oceânicas. Passemos aos instrumentos.

\section{O astrolábio, a agulha de marear e o desenho do Império}

Para o mar, melhor é dirigir-se pela altura do sol, que não por nenhuma estrela; e melhor com astrolábio, que não com quadrante nem com outro nenhum instrumento

(Faras, $1^{\circ}$ maio 1500).

A constatação acima faz parte da carta escrita pelo mestre João Faras, médico a bordo de um dos navios que formavam a esquadra de Pedro Álvares Cabral, registrando o descobrimento português no novo continente. Ao informar ao rei dom Manuel acerca das novas descobertas, o médico relatou que tomou a altura do Sol, em terra, ao meio-dia, do dia 27 de abril, com auxílio do "piloto do capitão-mor e o piloto Sancho de Tovar" (Faras, $1^{\circ}$ maio 1500). Após a realização dos cálculos necessários, indicou que as terras situavam-se a 17 graus de latitude Sul e aconselhou o rei que, caso ele tivesse interesse em "ver" as suas terras, bastava consultar um mapa mundi que tivesse à sua disposição. ${ }^{4}$

Ao encerrar a carta, no trecho em epígrafe, mestre João Faras afirmou que, entre os instrumentos usados na navegação oceânica, o astrolábio era o mais seguro e, entre as estrelas para observação, era o Sol. Isso se dava em função das dificuldades de observações noturnas de outros astros em função da instabilidade das embarcações. Nessa mesma carta, há também o registro gráfico da constelação do Cruzeiro, ainda que mestre João não aponte as coordenadas celestes das estrelas.

Os autores dos livros de marinharia por nós consultados tendiam a defender que, no mar, as observações para determinação de latitude são mais precisas quando feitas com o astrolábio e tomando a altura do Sol. Pimentel afirma que, entre os portugueses, o astrolábio é mais utilizado, mas informa que ingleses e holandeses preferiam utilizar o quadrante náutico. O mesmo defende João Batista Lavanha em seu texto, quando afirma que o problema das observações de latitude com o quadrante ou a balhestilha era a necessidade do horizonte 
como um dos pontos de mirada, fator complicador nas embarcações; tanto um como outro eram mais indicados para ler as alturas e distâncias entre as estrelas durante a noite. Ainda que outros instrumentos fossem utilizados, a predominância do astrolábio vem-se confirmando ainda a partir de levantamentos arqueológicos no fundo do mar, onde os astrolábios são encontrados em maioria nas embarcações de origem portuguesa (Reis, 1988).

Os astrolábios, ou quaisquer outros instrumentos, deveriam apresentar semelhanças na fabricação e graduação padronizada. Um mesmo tipo de instrumento podia ter pequenas variações no processo de confecção que implicavam formas distintas de uso, o que por sua vez acarretava cálculos diferentes na coleta e interpretação dos dados. Note-se que todo o procedimento, desde a coleta até a inserção dos dados em cartas de marear, roteiros e tabelas, era fruto de um trabalho conjunto que unia aqueles situados nas embarcações que atingiam os pontos mais remotos do Império e os cosmógrafos e cartógrafos que trabalhavam no Reino.

Aos cosmógrafos do Reino cabia o exame dos instrumentos que seriam utilizados pelos pilotos a serviço da Coroa. Um dos aspectos cruciais era a padronização da graduação e da forma de divisão, ${ }^{5}$ pois se os dados fossem coletados com unidades de medidas distintas, além de tornar a reunião dos dados dificultosa, multiplicar-se-iam os erros no momento de inserção dos dados em novas tabelas, nos roteiros e nos mapas-padrão.

Sobre a graduação do astrolábio, Simão de Oliveira, ${ }^{6}$ em sua Arte de navegar, explica em detalhes como o instrumento deveria ser graduado. Observa-se que o procedimento era pela subdivisão sucessiva das partes.

Descrito o astrolábio, resta dividi-lo, a qual divisão se fará desta maneira. Divide-se cada quadrante superior em três partes iguais, cada uma das quais se repartirá em outras três, e serão 9 e destas cada uma pelo meio e serão 18 que divididas cada uma em cinco ficará o quadrante dividido em 90 e cada uma das quais e ao centro do círculo, ajuntando uma régua se tirarão por elas linhas pequenas, lançando as que se tirarem de $10 \mathrm{em} 10$ graus, por ambos os intervalos e as de $5 \mathrm{em} 5$ por um intervalo e parte do outro e as de um em um por um intervalo só, fazendo um grau branco e outro preto, aos quais se lhe porão os números de 10 em 10 começando os do ponto A e acabando em C e D onde se porão 90. ... Descrito e dividido o astrolábio em papel passar-se-ão para o astrolábio em latão assim os círculos como as linhas em a mesma distância, divisão e número que tiveram em papel, descrevendo os círculos com um compasso de pontas de aço e as linhas com uma ponta do mesmo, para que corte o latão divisando os graus com umas riscas pequenas, assim como em papel se usa fazer um em branco e outro em preto (Oliveira, 1606, p.54-55).

De acordo com Manuel Pimentel (1681, p.36), a escolha de se colocar o ponto inicial referente ao zênite era uma característica do astrolábio português:

O astrolábio que usam os pilotos portugueses começa sua graduação em nada, ou cifra no Zênite, que é debaixo do arganel, e acaba em 90 graus no Horizonte assim para uma como para outra parte, ao contrário dos astrolábios castelhanos que começam a graduação em nada no Horizonte e acabam em 90 graus no Zênite. O nosso modo é melhor porque por ele fica mais fácil a conta das regras do Sol, que tratarei no capítulo seguinte.

A importância de explicitar a diferença entre as formas de graduar o instrumento ligavase tanto ao cálculo que deveria ser feito após a observação da altura do Sol como à consulta 


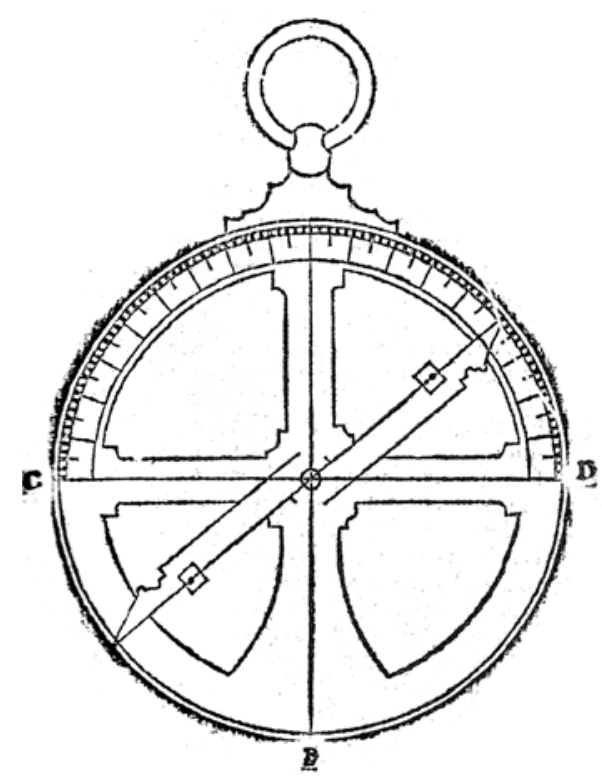

Figura 2: Astrolábio (Oliveira, 1606, p.57) das tabelas de declinação do astro. Verifica-se mais uma vez que havia de fato a necessidade de que os responsáveis pela coleta e condução das embarcações tivessem um preparo mínimo, fossem eles os pilotos ou capitães de um navio. Pois o uso correto de um instrumento exige o conhecimento básico dos princípios da esfera, até mesmo para o posicionamento do objeto. O mesmo pode ser dito sobre os fabricantes desses instrumentos, uma vez que o desenho deles e as formas de operação partiam igualmente das regras da esfera.

Verifica-se que o desenho do astrolábio náutico, sua forma de graduação e o posicionamento e o manejo do instrumento obedeciam aos elementos da esfera, em destaque no astrolábio o horizonte e o zênite, ambos relativos ao ponto de observação. O astrolábio permitia ainda, a partir da projeção da sombra do astro no instrumento, determinar

sua declinação. Tudo levado em consideração, constatada a distância que o Sol tem do zênite (astrolábio de uso português), sabida a declinação do Sol no dia da observação, o que contava também com auxílio de tabelas feitas para todos os dias do ano, e levando em consideração o hemisfério no qual o observador se encontrava, "entram as regras ordinárias para sabeis", segundo Pimentel (1681, p.39), "em que linha vos achais no mar".

Ainda sobre o astrolábio, Pimentel $(1819$, p.17) acrescenta que o lugar da embarcação para se tomar a altura do Sol "é ao pé do mastro grande por haver ali menos balanço". Alerta também que os graus devem ser anotados no momento correto, "entre um balanço e outro, por estar então em maior equilíbrio". Devem ser realizadas várias observações entre um quarto de hora antes do meio-dia e depois, assim pode se perceber quando o Sol "passa" pelo meridiano local atingindo a altura máxima.

Finalmente, afirmou que o instrumento foi inventado em Portugal, em tempo del Rei D. João II, por mestre Rodrigo, e mestre José, seus médicos, e por Martim de Bohemia, discípulo do grande João de Monte Regio, e por meio deste instrumento, feito a princípio de pau, é que os portugueses empreenderam os descobrimentos de terras incógnitas, e os conseguiram com grande glória sua (Pimentel, 1819, p.15).

O astrolábio existia desde a antiguidade, e acredita-se ter sido introduzido em Portugal durante a presença na península Ibérica de astrônomos, matemáticos e médicos de origem islâmica e judaica (Seed, 1999). O que ocorreu provavelmente em Portugal foi a adaptação do instrumento para uso no mar, que em vez de ser planisférico, fabricado para observação noturna das estrelas, passou a ter a forma anelada, viabilizando a observação do Sol, uma vez que permitia tomar a altura sem a necessidade de voltar os olhos para o astro. $\mathrm{O}$ anel graduado continha pínulas com orifícios por onde entrava a luz do Sol, propiciando a leitura dos graus no instrumento por meio de sua projeção. O que nos interessou na passagem foi a relação entre o instrumento e a glória de Portugal por meio das conquistas ultramarinas. 


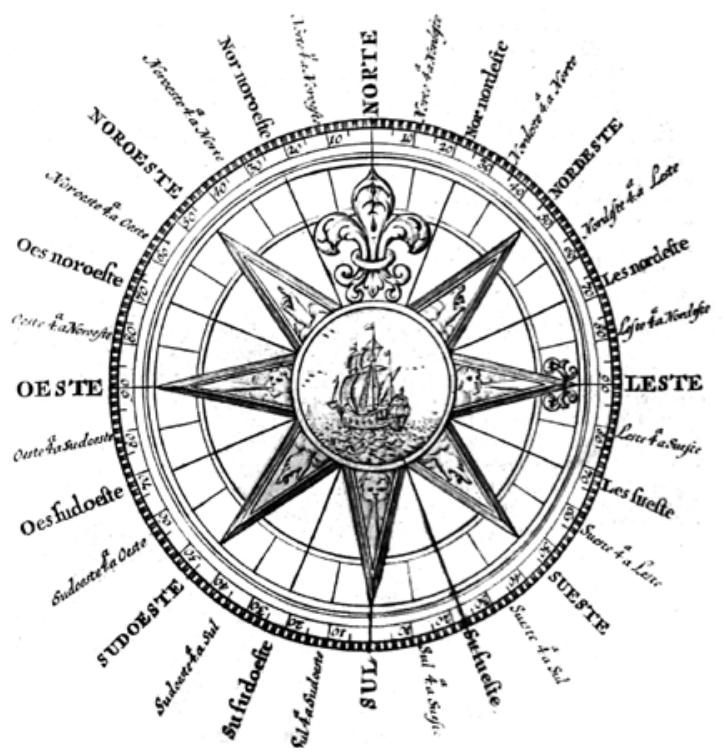

Figura 3: Destaque para o navio no centro da imagem que identifica os 32 ventos relacionados aos rumos marcados na agulha de marear (Pimentel, 1819, p.11)

Além do astrolábio, a agulha de marear era utilizada para ajustar o rumo que as embarcações deveriam seguir de acordo com os roteiros. No livro de Pimentel, o desenho da agulha de marear nos traz elementos importantes que são destacados.

Em primeiro lugar, o observador (representado pelo navio) está no centro, mas, nesse caso, o que importa é sua direção, e o círculo que está graduado representa o horizonte. O observador deve levar em consideração a existência de vários arcos que se entrecruzam no zênite. As regras de divisão que aparecem no círculo que representa o Horizonte novamente obedecem aos princípios da esfera, 360 e suas subdivisões, nesse caso formando 32 rumos distintos que servem também para classificar os ventos. "Por quaisquer dois pontos opostos do Horizonte, e pelo Zênite, se considera passar um círculo vertical, cujo plano corta o plano do Horizonte, e a tal cortadura é uma linha reta, a qual representa o rumo, que o navio descreve na superfície do mar, seguindo a direção da agulha" (Pimentel, 1819, p.8).

Ainda nos ensina Pimentel que, se nos roteiros os rumos são indicados pelo nome, nas cartas de marear são assinalados da seguinte forma: os principais que partem da primeira divisão em oito, norte e sul (representam o recorte do meridiano e horizonte; o leste e oeste, feito pela linha que passa no zênite e pelos pontos equinociais; e o nordeste-sudeste, noroeste-sueste, formados pelas divisões do horizonte, e verticais intermediários norte e sul, e "todos são assinalados nas cartas em linhas pretas". Segue a subdivisão desses oito em mais oito rumos, que são indicados nas cartas em "linhas verdes". Por sua vez, são subdivididos em 16 e assinalados nas cartas com "linhas vermelhas". Cada uma dessas divisões é numerada em graus e minutos. A unidade de divisão corresponde a 11 graus e um quarto, que, somados dentro de um quadrante da roda, ou seja, oito vezes, somam noventa graus (Pimentel, 1819, p.8).

As determinações do rumo apontado pela agulha também devem ser corrigidas, tanto em função da declinação magnética, quanto em relação à declinação do Sol. Apenas nos dias do equinócio, ou seja, duas vezes por ano, quando o Sol encontra-se na eclíptica, o astro nasce e se põe exatamente no leste e no oeste geográfico. De acordo com o hemisfério, a altura varia até 23 graus, tocando os paralelos de Câncer, no hemisfério Norte, e de Capricórnio, no hemisfério Sul, nos dias de solstício. Mais uma vez, coletados os dados, era indispensável a consulta de tabelas que forneciam os graus da amplitude ortiva e ocídua do Sol em cada dia do ano, cabendo ao observador realizar as devidas correções. 
A agulha de marear portuguesa, alocada numa caixa de madeira, segundo descrição de Pimentel era feita de forma a permitir a leitura dos graus de variação ortiva e ocídua do Sol devido aos orifícios existentes nos pontos leste e oeste.

A Agulha de demarcar Portuguesa tem a Rosa graduada em 360 graus repartidos em quatro vezes 90, os quais começam nos pontos de Norte, e Sul, acabando os 90 nos pontos de Leste Oeste, e vão contados de 5 em 5 . Tem mais a dita Rosa outros graus pelas ilhargas, escritos em umas tiras de papelão a modo de abas, grudadas na mesma circunferência da Rosa, que correspondem onde estão as frestas da caixa, ou morteiro, em que vai a Rosa sobre o ferro, ou aceiro cevado. Estes graus das abas das ilhargas começam nos pontos de Leste Oeste da Rosa, e continuam até 40, ou mais graus, assim para a banda do Norte, como do Sul (Pimentel, 1819, p.56).

Pelo dito morteiro, duas frestas com vidraças por meio das quais passa um fio por onde atravessa a luz do Sol ao nascer e ao se pôr. Exatamente no meio do fio era colocado um ponteiro permitindo que a luz do Sol lançasse uma sombra na circunferência da Rosa, apontando, se observado no instante da aurora ou do ocaso, a declinação do Sol. Após a coleta dos dados, eram, também nesse caso, necessárias tabelas e aplicação dos cálculos para se determinar corretamente a variação da agulha. Dessa forma, as embarcações, conduzidas por homens que seguiam corretamente os caminhos descritos nos roteiros e guiavam-se pelos lugares e informações assinalados em cartas de marear, com auxílio do astrolábio e da agulha, cruzavam os mares e percorriam as rotas que ligavam as terras pertencentes a Portugal.

As cartas de marear desenhadas pelos cosmógrafos-mores eram entregues aos pilotos ou, ocasionalmente, para aqueles que prestavam serviços ao rei no ultramar e eram versados em cosmografia, como o caso de Martim Afonso de Sousa ou dom João de Castro, entre tantos outros. Cabia a esses homens, eventualmente, corrigir ou atualizar os dados contidos nas cartas. Porém, no processo de catalogação das informações e na transposição dessas para as cartas de marear oficiais, quem detinha a autoridade para decidir eventuais discordâncias eram os cosmógrafos do Reino. Não era incomum a discordância entre pilotos e cosmógrafos, mas os últimos tinham a autoridade - tanto intelectual quanto pela hierarquia do cargo - para decidir. Lembremos que muitas vezes as localizações exatas de pontos estratégicos eram objeto de disputa entre os Estados, o que era levado em consideração pelo funcionário real, nesse caso, os cosmógrafos e cartógrafos (Portuondo, 2009; Sandman, 2002).

O uso correto da carta exigia uma série de cálculos na hora de traçar o rumo da embarcação, o que poderia ser extraído da própria carta com auxílio de um compasso de ponta seca e observando o "tronco", que informava a escala. Mesmo na carta plana, que segundo Pimentel era a mais usada em seu tempo, a dificuldade era a diferença entre aquilo que é visto nas cartas e a linha verdadeiramente traçada pelo deslocamento do navio: enquanto na carta a linha é representada por uma reta, o rumo traçado no mar pela embarcação descreve uma porção de arco, daí a exigência, mais uma vez, de uma série de cálculos geométricos e trigonométricos. Além dos rumos, os cálculos permitiam a determinação da longitude dos lugares a partir das distâncias percorridas.

Pimentel descreve detalhadamente três tipos de carta de marear. Entre elas, destaca que a mais utilizada era a carta plana ou comum. Essas, segundo o cosmógrafo, eram as mais utilizadas entre os pilotos portugueses. Confeccionadas a partir de linhas paralelas 
representando as coordenadas de latitude e longitude e postas de forma equidistante no papel, as cartas planas visavam facilitar o dia a dia de uma viagem. Ajudavam também os pilotos a conduzir a embarcação seguindo os rumos preestabelecidos nos roteiros. Essa carta era desenhada por derrotas e alturas; nela se colocavam as terras em seus sítios a partir da experiência, ou seja, a partir das tabelas das latitudes e longitudes dos lugares conhecidos.

Alguns procedimentos deveriam ser seguidos na confecção das cartas. Em primeiro lugar, era comum dispor no papel um número significativo de rosas dos ventos, lançando os 32 ventos que tinham o mesmo nome que os rumos postos na rosa das agulhas. A flor-de-lis indicando sempre o norte. Além dos rumos, são lançadas as linhas que representam os círculos paralelos e os círculos meridianos, que são representadas de forma equidistante. Para fazer a carta em escala, um dos meridianos era dividido em graus iguais, de tamanhos idênticos, iniciando desde o Equador, cada grau subdividido em três ou quatro conforme o tamanho da carta. Desses graus era feito o tronco de léguas ou petipé, pelo qual era possível medir a distância dos lugares em escala.

Segundo Pimentel, entre os portugueses era comum atribuir 18 léguas a cada grau do arco meridiano e, em função disso, saber se a carta está posta corretamente:

Se repartem os quatro graus do Meridiano em 72 partes iguais, cada uma fica valendo uma légua. O tronco faz-se de 100, 150 ou 200 léguas. E um dos exames da carta para se ver se está certa, e tomar 4 graus do Meridiano entre as pontas do compasso, e pondo-o sobre o tronco de léguas, se ajustar 72 nas [cartas] que se usarem daqui por diante, estará o tronco ou petipé correto (Pimentel, 1819, p.70).

Outro procedimento era verificar se, em cada rosa disposta sobre a carta, os rumos do mesmo nome estão paralelos entre si. Em caso positivo, a carta "estará bem compassada" (Pimentel, 1819, p.70). Algumas informações devem ser assinaladas: a figura de uma âncora indica o local onde se pode ancorar; pirâmides pequenas apontam a existência de pedras ou lajes que o mar não cobre; cruzes avisam sobre pedras que ficam ocultas, embaixo d'água; muitos pontinhos representam bancos de areia; muitas cruzes pequenas junto com pontinhos alertam sobre as restingas de pedra; finalmente, algarismos indicam os fundos ou braças de águas que há nas praias ou portos. Por fim, conclui Pimentel que as cartas previnem sobre quatro coisas:

A primeira é a arrumação de uma costa, ou de uma terra ou outra. A segunda a distância de léguas, que há numa parte a outra. A terceira o grau de altura dos polos, ou o apartamento da linha em que está cada terra, ilha, cabo ou baixo. A quarta é o ponto ou lugar em que a nau se acha, depois de haver navegado algum tempo (Pimentel, 1819, p.71).

O último tópico tratado por Pimentel inclui as explicações e previsões das fases da Lua acompanhadas de tabelas que permitiam a previsão de marés em diversos portos ultramarinos por meio de cálculos. Por fim, também relacionado às fases lunares e não de menor importância no Império português, o calendário das festas móveis e dias santos celebrados pelos católicos.

\section{Considerações finais}

A segunda parte do livro de Pimentel se constitui de roteiros para navegação de Portugal para as Índias e regiões do Índico; em seguida o roteiro de navegação de Portugal para o 
Brasil e detalhamento da costa desde o Maranhão até o rio da Prata. Tais roteiros eram feitos a partir dos livros anteriores, acrescidos de informações que chegavam do ultramar, o que permitia em alguns casos a atualização e correção dos dados. Os cosmógrafos do rei tinham acesso ao material que era entregue pelos pilotos, segundo Pimentel, à "Secretaria do Estado"; o detalhamento da rota é minuciosamente informado.

No roteiro relativo ao Brasil, por exemplo, Pimentel indica que, saindo do Rio de Janeiro em direção a Buenos Aires, entre novembro e março, época das monções, e rumando para o rio da Prata, a nau deve ser direcionada para o sul atingindo a altura de 28 graus. Desse ponto em diante, o piloto deve seguir para sudoeste, de maneira a ficar afastado da costa aproximadamente 45 léguas chegando a altura de 34 graus e meio ou 35, caso o vento seja de Leste para Noroeste. E, em caso de sair do Rio de Janeiro entre os meses de abril e setembro, a embarcação deve rumar para o sul até 29 graus de altura e, desse ponto, conduzir a nau a 50 léguas distante da costa alcançando a altura de 35 graus e meio. Desse ponto em diante, seguir rumando para Oeste observando a variação da agulha. Ele conclui que "De abril em diante é melhor ir mais apartado da costa porque os ventos Suestes e Suis são travessia e vêm com muita força no primeiro ímpeto, levantando grandes marés" (Pimentel, 1819, p.329).

Como tantos outros cosmógrafos, Manuel Pimentel não realizou viagens oceânicas. Porém, quando se verificam a quantidade e a qualidade de informações presentes nos livros de marinharia não é errado concluirmos que, nas embarcações, o piloto, ou quem quer que fosse, controlasse minimamente conceitos básicos da esfera e dos cálculos que permitiam usar corretamente o astrolábio, a agulha, as tabelas e as cartas de marear.

Embora existam erros de localização nas cartas de marear e nas tabelas de latitude e longitude dos lugares inseridas nos livros, lembremos que podem fazer parte de interesses territoriais e eram estrategicamente distorcidos pelos cosmógrafos. Portanto, tais erros não devem ser imediatamente atribuídos por nós à má formação e preparo dos pilotos que cruzavam o Atlântico em nome de Portugal como reclamavam os cosmógrafos, ainda que houvesse a dificuldade da realização de cálculos e de procedimentos mais complexos por parte dos homens do mar.

Não era rara a divergência entre a informação que retornava nas naus e a dos cosmógrafos, o que tendia, de acordo com a situação, a ser resolvido pela autoridade dos cosmógrafos. Registro apenas que isso não deve ser entendido como uma falha estrutural na formação dos pilotos portugueses. Os dados sobre a localização dos lugares eram elemento de disputa entre os Estados europeus, portanto não devemos entender a prática dos cosmógrafos como isenta dos interesses políticos na hora da elaboração de cartas e roteiros e da fixação de lugares estratégicos. Ainda que um piloto não precisasse ser versado nas principais polêmicas da época no campo da matemática ou da astronomia, alguns princípios básicos faziam-se necessários, sobretudo para a manipulação correta dos instrumentos.

Dessa forma, por meio dos cálculos feitos com uso do astrolábio, da agulha, da consulta de tabelas, da consulta aos roteiros que determinavam as rotas e pela leitura das cartas de marear, os pilotos ou os capitães das embarcações conduziam os homens e produtos que circulavam pelo Império português. Em seu turno, as cartas de marear, com as informações necessárias sobre a costa, permitiam que o cosmógrafos fossem responsáveis pelo desenho do Império. 


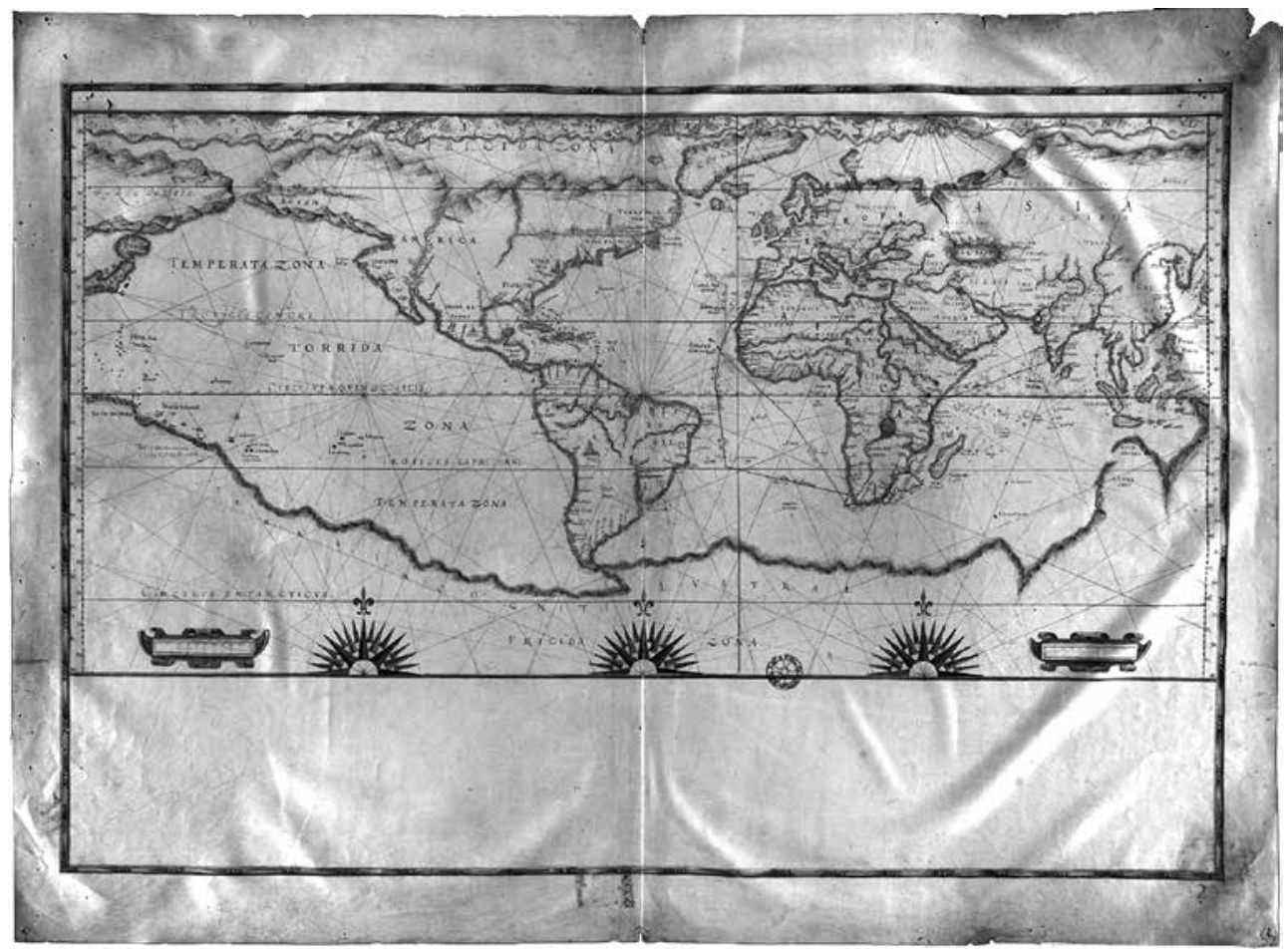

Figura 4: Nessa carta, além das linhas de rumo marcada pelas rosas dos ventos dispostas em vários lugares, destacamos a linha Equinocial e os trópicos de Câncer e Capricórnio. Podemos perceber algumas rotas de navegação que ligavam as partes do Império (Albernaz I, c.1632, folha 1)

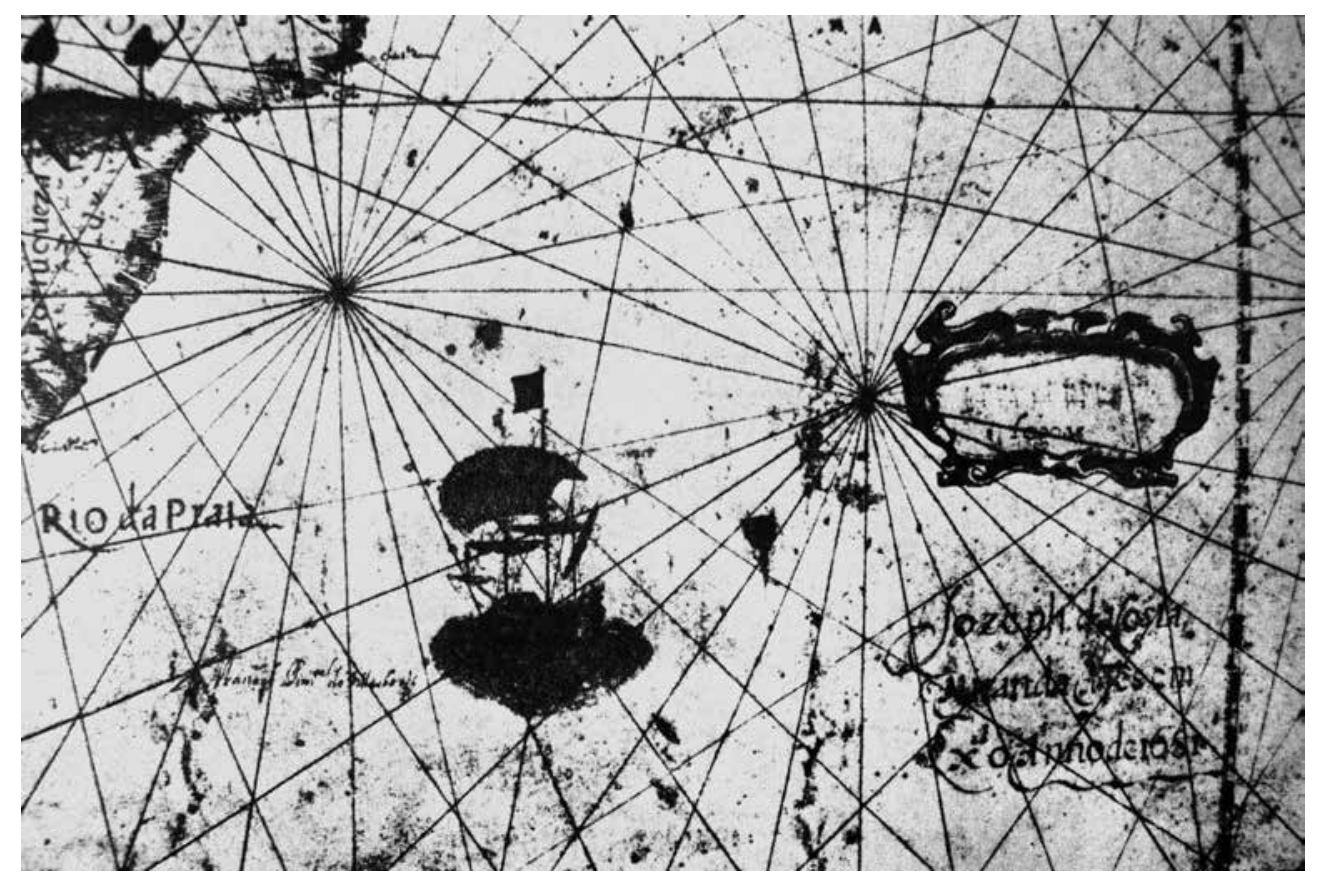

Figura 5: Detalhe de uma Carta do Atlântico, c.1681, de autoria de Manuel Pimentel de Villasboas e José da Costa Miranda. Embaixo à esquerda podemos ver a assinatura de Manuel Pimentel de Villasboas (Cortesão, Mota, 1987, estampas 568, 569) 


\section{NOTAS}

${ }^{1}$ Entendemos os descobrimentos como práticas presentes nas navegações dos séculos XV ao XVIII que resultam das viagens e ao mesmo tempo as condicionam. Tais viagens são preparadas e contam com o apoio direto ou indireto do Estado, e delas retorna para a Europa um conjunto de informações, desde notícias geográficas até dados de interesse mercantil. A partir do deslocamento, amplia-se o conhecimento sobre os espaços navegados, que são registrados em roteiros e mapas-padrão, reúnem-se técnicas e articulam-se, do ponto de vista cultural e científico, as transformações ocorridas durante o Renascimento (Godinho, 1994; Barreto, 1989; Dias, 1973; Albuquerque, 1987, 1989; Cañizares-Esguerra, 2006; Smith, Findlen, 2002).

${ }^{2}$ Utilizamos neste trabalho a edição de 1818, disponível na Biblioteca Nacional, no Rio de Janeiro, em bom estado para consulta.

${ }^{3}$ Nossa hipótese de que Pimentel opta por não apresentar outras teorias, como faz em outras passagens da obra sobre outros temas, justifica-se por ser intencionalmente escrita para ensinar as bases matemáticas para navegação, e o centro coincide com o observador. Ainda que ele fosse de fato um defensor do geocentrismo, o que na época ainda era provável num egresso do Colégio de Santo Antão, o fato de nem sequer mencionar a estrutura com base no modelo de Tycho Brahe, incorporado oficialmente pela Companhia de Jesus, nos leva a crer que o autor de fato não achou interessante entrar na polêmica. Isso não deve ser entendido por nós hoje simplesmente como um indício de defasagem na cultura científica em Portugal na virada do século XVII para o XVIII, momento da primeira edição do livro de Newton, mas apenas como uma intenção clara de Pimentel de não entrar na polêmica, pelo menos em sua Arte de Navegar.

${ }^{4}$ Apenas para informar o leitor, a cidade de Porto Seguro localiza-se a $16^{\circ} 26^{\prime} 59^{\prime \prime}$ de latitude Sul.

${ }^{5}$ Entre os séculos XVI e XVIII um dos problemas enfrentados pelos fabricantes de instrumentos de medição recaía justamente na divisão das unidades de medida no próprio instrumento, não havia uma maneira de garantir que todos os intervalos fossem, de fato, idênticos. Embora Pedro Nunes tivesse proposto a solução da divisão em escala por meio do nônio, na época era impossível a sua execução no processo de fabricação. Só entre as décadas de 1760 e 1770, Jesse Ramsden criou uma máquina que fazia mecanicamente a divisão de escalas circulares (Reis, 1999, p.67).

${ }^{6}$ Simão de Oliveira, cosmógrafo-mor entre os séculos XVI e XVII. Seu livro, $A$ arte de navegar, publicado em 1606, traz longos trechos das anotações de aula do padre Francisco da Costa, matemático jesuíta que lecionou no Colégio de Santo Antão (Albuquerque, 1989).

\section{REFERÊNCIAS}

ALBERNAZ I, João Texeira.

[Atlas Universal]. Folha 1. Disponível em: http:// objdigital.bn.br/acervo_digital/div_cartografia/ cart1004846.pdf. Acesso em: 12 ago 2014. [c.1632].

ALBUQUERQUE, Luis de. A náutica e a ciência em Portugal: notas sobre as navegações. Lisboa: Gradiva.1989.

ALBUQUERQUE, Luis de.

As navegações e sua projeção na ciência e na cultura. Lisboa: Gradiva. 1987.

ALBUQUERQUE, Luís de.

A "Aula da Esfera" do Colégio de Santo Antão no século XVII. Coimbra: Junta de Investigação do Ultramar. 1972.

ALBUQUERQUE, Luís de.

Sobre um manuscrito quatrocentista do Tratado da Esfera, de Sacrobosco. Revista da Faculdade de Ciências da Universidade de Coimbra, v.28, p.142156. 1959.
BARRETO, Luís Filipe.

Os Descobrimentos e a ordem do saber: uma análise sociocultural. Lisboa: Gradiva. 1989.

BLUTEAU, Raphael.

Vocabulário português e latino, áulico, anatômico, arquitetônico..., v.4. Coimbra: Collegio das Artes da Companhia de Jesus. Disponível em: http:// www.brasiliana.usp.br/dicionario/edicao/1. Acesso em: 9 set. 2012. 1728.

BOXER, Charles.

O Império marítimo português (1415-1825). Lisboa: Edições 70. 1992.

CAMENIETZKI, Carlos Ziller. Introdução. In: Sacrobosco, Johannes de. Tratado da esfera. Tradução Pedro Nunes; atualização para o português contemporâneo Carlos Ziller Camenietzki. São Paulo: Unesp. p.2-15. 2011.

CAÑIZARES-ESGUERRA, Jorge.

Nature, empire and nation: exploration of the history of science in the Iberian world. Stanford: Stanford University Press. 2006. 
CORREIA, Carlos Alberto Calinas.

$A$ arte de navegar de Manuel Pimentel (as edições de 1699 e 1712). Dissertação (Mestrado em História dos Descobrimentos e da Expansão) - Faculdade de Letras, Universidade de Lisboa, Lisboa. 2010.

DIAS, José S. da Silva.

Os descobrimentos e a problemática cultural do século XVI. Lisboa: Presença. 1973.

FARAS, João, mestre.

Carta de mestre João a dom Manuel I sobre o Cruzeiro do Sul. Inventário "Corpo cronológico"; P.3, M.2, doc.2; PT/TT/CC/3/02/02 (Arquivo Nacional da Torre do Tombo, Lisboa). $1^{\circ}$ maio 1500 .

FURTADO, Junia.

Oráculos da geografia iluminista: D. Luis da Cunha e Jean-Baptiste Bourguignon D'Anville na construção da cartografia do Brasil. Belo Horizonte: Editora UFMG. 2011.

GODINHO, Vitorino Magalhães. O papel de Portugal nos séculos XV-XVI: Que significa descobrir? Os novos mundos e um mundo novo. Lisboa: Grupo de Trabalho do Ministério da Educação para as Comemorações dos Descobrimentos Portugueses. 1994.

GUEDES, Max Justo.

Portugal e o mar. Oceanos, n.38, p.8-15. abr.-jun. 1999.

\section{KANTOR, Iris.}

Cultura cartográfica e gestão territorial na época da instalação da corte portuguesa. In: Kury, Lorelai; Gesteira, Heloisa (Org.). Ensaios de história das ciências no Brasil: das luzes à nação independente. Rio de Janeiro: Eduerj. p.239-250. 2012.

LEITÃO, Henrique.

Jesuit mathematical practice in Portugal, 15401759. In: Feingold, Morderchai (Ed.). The new science and Jesuit science: seventeenth century perspectives. Dordrecht: Kluwer. 2003.

MATOS, Rita Cortez de.

O cosmógrafo-mor: o ensino náutico em Portugal nos séculos XVI e XVII. Oceanos, n.38, p.55-64. abr.-jun. 1999.

MOTA, Avelino Teixeira da.

Os regimentos do cosmógrafo-mor de 1559 e 1592 e as origens do ensino náutico em Portugal. Lisboa: Junta de Investigações do Ultramar. 1969.

OLIVEIRA, Simão de.

Arte de navegar. Lisboa: Oficina de Pedro Crasbeeck. 1606.
PIMENTEL, Manuel.

Arte de navegar em que se ensinam as regras práticas, e os modos de cartear, e graduar a balestilha por via de número e muitos problemas úteis a navegação e Roteiro das viagens e costas marítimas de Guiné, Angola, Brazil, Indias, Ilhas Orientais e Ocidentais. Novamente emendado e acrescentado muitas derrotas. Lisboa: Tipografia de Antonio Rodrigues Galhardo. 1819.

PIMENTEL, Manuel.

Arte prática de navegar e regimento de pilotos repartido em duas partes a primeira propositiva em que se propõem alguns princípios para melhor inteligência das regras de navegação: a segunda operativa em que se ensinam as mesmas regras para a prática: juntamente os roteiros das navegações das conquistas de Portugal, e Castela. Lisboa: Antonio Craesbeeck de Melo. 1681.

PORTUONDO, Maria.

Lunar eclipse, longitude and the New World. Journal of the History of Astronomy, v.40, n.3, p.249-276. 2009.

REIS, António Estácio dos.

O nônio de Pedro Nunes. Oceanos, n.38, p.66-80. abr.-jun. 1999.

REIS, António Estácio dos.

O quadrante náutico. Revista da Universidade de Coimbra, v.34, separata, p.243-273. 1988.

ROSSI, Paolo.

Os filósofos e as máquinas. São Paulo: Companhia das Letras. 1989.

SANDMAN, Alison.

Mirroring the world: sea charts, navigation and territorial claims in sixteenth-century Spain. In: Smith, Pamela; Findlen, Paula (Ed.). Merchants and marvels: commerce, science and art in Early Modern Europe. New York: Routledge. p.83-108. 2002.

SEED, Patricia.

Cerimônias de posse na conquista da europeia do Novo Mundo (1492-1640). São Paulo: Unesp. 1999.

SMITH, Pamela; FINDLEN, Paula (Ed.).

Merchants and marvels: commerce, science and art in Early Modern Europe. New York: Routledge. 2002.

VASCONCELOS, Simão de.

Crônica da Companhia de Jesus do Estado do Brasil. Rio de Janeiro: Tipografia de João Ignacio da Silva. 1864.

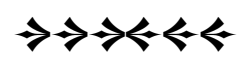

